\title{
Mujer inmigrante y mercado laboral en el País Vasco: un acceso precario al empleo
}

\author{
María José Martín Herrero \\ Ikuspegi-Observatorio Vasco de Inmigración. \\ Universidad del País Vasco (UPV/EHU) \\ <mjmh_2001@yahoo.es>
}

\begin{abstract}
Arkaitz Fullaondo Elordui-Zapaterietxe
Ikuspegi-Observatorio Vasco de Inmigración. Universidad del País Vasco (UPV/EHU)
\end{abstract}

\section{Gorka Moreno Márquez}

Ikuspegi-Observatorio Vasco de Inmigración. Universidad del País Vasco (UPV/EHU)

Artikulu honen helburua Euskal Autonomia Erkidegoko lan-merkatuan emakume etorkinaren errealitatea eta egoera ezagutzea da. Zehazki, bere lan-egoera aztertu egiten da, lan-sektoreak, ohiko arazoak, asebetetze maila edota emakume etorkin langabetuen ezaugarriak. Horretarako Eusko Jaurlaritzak EAEko populazio etorkinari egindako inkesta (2010) aztertu egiten da eta horretan oinarriturik Ikuspegi-Immigrazioaren Euskal Behatokiak egindako emakume etorkinari buruzko txostena. Ondorio nagusienen artean nabarmentzen da emakume etorkina eta etxeko lan eta zainketen arteko harremana. Zentzu honetan, gauzatzen ari den ereduan emakume etorkina ongizate-arloan dauden erronkei erantzuteko ardatzetako bat da, bereziki bertako populazioaren beharrizanen aseketan.

\section{HITZ-GAKOAK:}

Emakumea, immigrazioa, ongizatea, lan merkatua, estatistika-datuak.
Este artículo tiene como objetivo conocer la situación de la mujer inmigrante en el mercado laboral en la Comunidad Autónoma de Euskadi. En concreto, se analiza su situación laboral: sectores en los que trabaja, problemas habituales, grado de satisfacción y la situación de las mujeres inmigrantes desempleadas. Para ello, se analiza la información que ofrece la Encuesta de la Población Inmigrante en Euskadi (EPIE 2010) referida al ámbito laboral, así como el estudio Mujer inmigrante en la CAPV 2010, realizado por Ikuspegi-Observatorio Vasco de la Inmigración. Este estudio pone de manifiesto cómo emerge un modelo en el que la inserción laboral precaria de la mujer inmigrante en el sector de las tareas domésticas y los cuidados personales va a ser uno de los ejes para el mantenimiento de las cotas de bienestar actual de la población autóctona.

\section{Palabras clave:}

Mujer, inmigración, bienestar individual, mercado laboral, datos estadísticos. 


\section{Introducción. Objetivos y metodología}

En la primera parte del artículo, presentamos las principales conclusiones del estudio Mujer inmigrante en la CAPV 2010, realizado por Ikuspegi-Observatorio Vasco de Inmigración ${ }^{1}$. Se realiza una descripción de las mujeres inmigrantes teniendo en cuenta las características sociodemográficas del colectivo, su proceso migratorio, su situación de bienestar, su grado de integración en la Comunidad Autónoma de Euskadi (CAE) y sus perspectivas de futuro.

La segunda parte del artículo analiza, por un lado, la situación la mujer en el mercado laboral en la CAE: relación con la actividad, rasgos de las mujeres ocupadas teniendo en cuenta la rama de actividad donde trabajan, tipo de contrato, tipo de profesión, ocupación e indicadores que nos muestran su situación en el mercado de trabajo. Y en esta segunda parte, se examina asimismo la situación de la mujer desempleada, las estrategias de búsqueda de empleo y la experiencia entre las que han trabajado en el último año.

Para concluir, se presenta una caracterización de las mujeres inmigrantes en la CAE atendiendo a su grado de integración social y laboral. A modo de prospectiva, se plantea además el modelo de integración de las mujeres inmigrantes en la CAE que va a prevalecer en los próximos años.

La metodología utilizada para realizar el estudio ha sido la explotación de la Encuesta de la Población Inmigrante residente en la Comunidad Autónoma de Euskadi (EPIE) ${ }^{2}$. Se trata de una operación estadística realizada por el Gobierno Vasco que nos ofrece una nítida fotografía de las características del colectivo. Esta encuesta se ha realizado sobre una muestra de 2.300 personas de origen extranjero y se ha recogido tanto un cuestionario individual como otro familiar. Se ha elaborado siguiendo una estratificación por origen y municipio de residencia, con un error muestral de $\pm 1,59$ para el conjunto de la encuesta.

\section{Mujer inmigrante en la CAE. Características generales}

Según la encuesta de Población Inmigrante en Euskadi (EPIE) 2010, la población de origen extranjero residente es de 179.582 personas, lo que supone un $8,2 \%$ de la población total. Las mujeres inmigrantes en la CAE son 92.598 personas y representan el $51,6 \%$ del colectivo de origen extranjero, mientras que los hombres son 86.984 personas y suponen el $48,4 \%$. Esta distribución resulta ligeramente más feminizada que la correspondiente a los datos recogidos en el padrón de 2011, donde las mujeres

${ }^{1}$ María José Martín, Gorka Moreno y Arkaitz Fullaondo, Mujer inmigrante en la CAPV, Bilbao, Ikuspegi-Observatorio Vasco de Inmigración, 2012.

2 Siguiendo el tipo de cálculo realizado por la EPIE, los datos que se muestran a lo largo del informe se refieren a la población de origen extranjero de entre 16 y 66 años. representan el $48 \%$ del colectivo y los hombres el $52 \%$.

Al comparar los datos de la EPIE 2010 y los ofrecidos por el INE, podemos apreciar la diferencia existente entre población extranjera y población inmigrante de origen extranjero, con un peso cada vez mayor de las nacionalizaciones en los procesos migratorios. $\mathrm{Y}$ a su vez, se pone de manifiesto la importancia de una encuesta como la EPIE, que nos ofrece una imagen mucho más certera y exacta del fenómeno migratorio en la CAE (Gobierno Vasco, 2011).

Mientras que los datos del padrón indican que la población masculina extranjera es mayoritaria, si nos atenemos a los de la EPIE observamos que la femenina es mayor. Esta variación se da como consecuencia de las ya citadas nacionalizaciones y, en particular, se debe a que, dentro de éstas, es mucho mayor el número de personas de origen latinoamericano, grupo en el que prevalecen las mujeres. Éste es un dato resaltable, ya que frente a procesos migratorios anteriores o visiones que hacen hincapié en la prevalencia masculina de los procesos migratorios, en el caso de la CAE se rompe con este esquema.

Así, la inmigración acogida en la CAE tiene rostro de mujer cuando se analiza el colectivo llegado de Latinoamérica, y de hombre en el caso de las personas provenientes del continente africano (Magreb, Senegal). Las situaciones más equilibradas corresponden a Rumanía y demás países orientales de la UE, así como a Argentina, Chile, Uruguay y China.

Entre las 92.598 mujeres que contabiliza la EPIE, destacamos los dos grupos mayoritarios: el primero está formado por mujeres de origen colombiano, ecuatoriano y peruano (18.674); y el segundo, por mujeres magrebíes (11.139). Ambos suponen el $16,6 \%$ del total de la población inmigrante en la CAE y el $32,2 \%$ de las mujeres inmigrantes.

Con respecto a la edad, la población de origen extranjero es más joven que la autóctona y en ella escasean las personas mayores de 65 años. El colectivo de hombres es ligeramente más joven que el de las mujeres.

El nivel de estudios de las mujeres inmigrantes es ligeramente superior al de los hombres, y la gran mayoría tiene estudios secundarios. Sin embargo, hay grandes diferencias entre las distintas áreas de origen. Así, nos encontramos con un bajo porcentaje de mujeres magrebíes, senegalesas y chinas con estudios cualificados, frente a las de la UE occidental, Argentina, Chile y Uruguay, que sí los tienen.

Entre las lenguas más utilizadas, destaca en primer lugar el castellano, siendo las mujeres las que más lo usan, con un $63,2 \%$ frente al 54,4\% de los hombres. El mayor uso por parte de las mujeres se debe a la mayor relevancia entre éstas de las mujeres provenientes de Latinoamérica, que en su mayoría hablan el castellano en su país de origen. 
Tabla 1. Distribución de la población de origen extranjero3, por áreas de origen y sexo. Índice de feminización. CAE, 2010

\begin{tabular}{|c|c|c|c|c|c|c|}
\hline \multirow[b]{2}{*}{ Área de origen } & \multicolumn{3}{|c|}{ Población inmigrante } & \multicolumn{3}{|c|}{ Índice de feminización } \\
\hline & Hombre & Mujer & Total & $\%$ vertical & $\%$ horizontal & \\
\hline Resto de América Latina & 2.525 & 6.798 & 9.323 & 7,3 & 72,9 & dominio femenino \\
\hline Brasil, Venezuela, Rep. Dominicana & 5.201 & 9.117 & $14 \cdot 318$ & 9,8 & 63,7 & mayoría femenina \\
\hline Paraguay & 2.167 & $3 \cdot 380$ & $5 \cdot 547$ & 3,7 & 60,9 & mayoría femenina \\
\hline Bolivia & 5.780 & 8.090 & 13.870 & 8,7 & 58,3 & mayoría femenina \\
\hline Colombia, Ecuador, Perú & $14 \cdot 358$ & 18.674 & 33.031 & 20,2 & 56,5 & mayoría femenina \\
\hline Argentina, Chile, Uruguay & 3.919 & 4.149 & 8.068 & 4,5 & 51,4 & equilibrio \\
\hline Rumanía y otros países de la UE oriental & 9.059 & 9.568 & 18.627 & 10,3 & 51,4 & equilibrio \\
\hline Resto del mundo & 5.937 & 5.565 & 11.502 & 6,0 & 48,4 & equilibrio \\
\hline China & 2.546 & 2.288 & 4.833 & 2,5 & 47,3 & equilibrio \\
\hline Resto de África & 4.500 & 3.951 & 8.450 & 4,3 & 46,8 & equilibrio \\
\hline UE occidental & 12.264 & 9.161 & 21.426 & 9,9 & 42,8 & mayoría masculina \\
\hline Magreb & 16.148 & 11.139 & 27.287 & 12,0 & 40,8 & mayoría masculina \\
\hline Senegal & 2.583 & 718 & $3 \cdot 301$ & 0,8 & 21,8 & dominio masculino \\
\hline Total & 86.985 & 92.598 & 179.583 & 100,0 & 51,6 & equilibrio \\
\hline
\end{tabular}

Fuente: Elaboración propia a partir de la EPIE 2010.

\section{Gráfico 1. Mujeres inmigrantes, por situación legal y área de origen. CAE, 2010 (\%)}

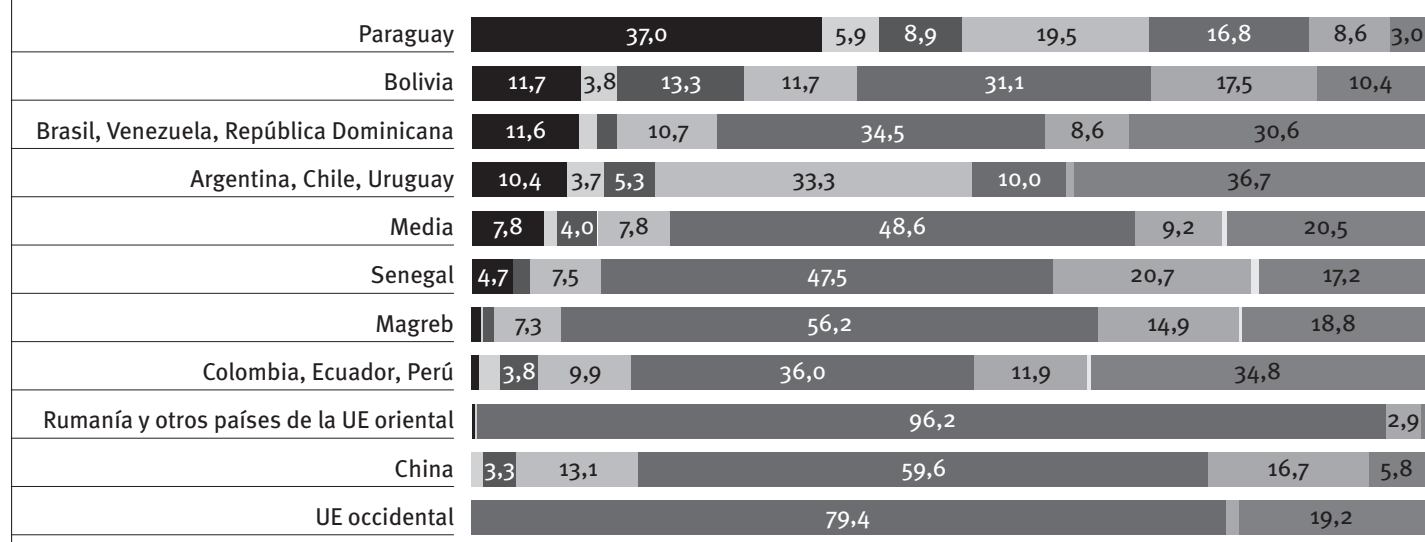

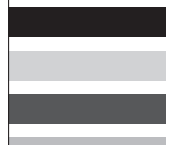

Irregular

Permiso de trabajo inicial

Permiso de trabajo $1^{\underline{a}}$ renovación

Permiso de trabajo 2 a renovación
Permiso de residencia permanente

Permiso de residencia (no de trabajo)

Irregular sobrevenido

Nacionalidad española

Fuente: Elaboración propia a partir de la EPIE 2010. 


\subsection{El proceso migratorio}

La situación administrativa de la mujer inmigrante es un indicador muy importante para conocer el grado de inserción del colectivo, estrechamente vinculado al tiempo de estancia. Estos dos aspectos están relacionados de tal forma que a mejor situación administrativa y mayor periodo de estancia, mejores indicadores de integración tienen las mujeres inmigrantes, y a la inversa. Esta relación es la que hemos venido a denominar en el Observatorio Vasco de Inmigración como 'continuum de estabilidad' (Moreno y Aierdi, 2011).

Las nacionalizaciones en las mujeres inmigrantes se han dado, sobre todo, entre las nacionalidades latinoamericanas. Este hecho se debe, en gran parte, a la diferente regulación existente en esta materia dependiendo de la procedencia. Así, mientras que la población latinoamericana puede solicitar la nacionalidad española tras demostrar dos años de residencia autorizada, este plazo aumenta, por ejemplo, a diez años para la población africana o asiática.

\subsection{Bienestar individual}

\subsection{1. ¿Cuál es la principal fuente de ingresos de las mujeres inmigrantes?}

El origen principal de sus ingresos son los derivados del trabajo. Además, en el caso de las mujeres bolivianas y paraguayas, los ingresos son superiores a los hombres de su misma nacionalidad. Este dato incide en un aspecto llamativo: la mujer inmigrante tiene, en muchas ocasiones, más facilidades para acceder al mercado laboral en la CAE que los hombres. En el caso de la población latinoamericana, esta característica es manifiesta.

\subsection{2. ¿Cuánto ganan? ¿Qué percepción tienen sobre su situación económica?}

Los ingresos per cápita de las mujeres inmigrantes por áreas de origen, junto con la valoración de la situación económica de su hogar, nos permiten tener una idea de las diferencias que se establecen a partir de las distintas procedencias y su bienestar individual. Así, a partir de las preguntas del cuestionario sobre los ingresos y la pregunta 'Percepción de la situación económica del hogar a partir de sus medios económicos', se establecen dos grupos:

- Mujeres con altos ingresos y valoración favorable de su situación económica del hogar. En este grupo se encuentran las mujeres provenientes de China, UE occidental, Argentina, Chile y Uruguay, con unos ingresos per cápita superiores a 900 euros/mes y una percepción favorable de sus medios económicos.

- Mujeres con bajos ingresos y percepción desfavorable o muy desfavorable sobre los medios económicos del hogar. En este grupo se encuentran las mujeres africanas, magrebíes, senegalesas y del resto de África. Presentan grandes dificultades económicas las magrebíes, con unos ingresos medios de 648 euros/mes y una percepción muy desfavorable de su situación económica. También destacamos la particularidad de algunas procedencias, como las bolivianas y paraguayas, ya que, aunque tienen unos ingresos per cápita inferiores a la media y una percepción desfavorable sobre su situación económica, disponen de unos ingresos superiores a los hombres de su misma nacionalidad.

\subsection{3. ¿Cuáles son sus principales problemas en el ámbito social y de salud?}

Los dos problemas principales que tienen las mujeres inmigrantes son: rechazo social por su condición de extranjeras (28,4\%), y problemas de soledad y tristeza $(17,9 \%)$. Estos problemas se dan prácticamente igual entre los hombres inmigrantes. No obstante, la separación de algún familiar, la enfermedad crónica grave y la existencia de personas dependientes, aunque no son los principales problemas, sí se dan con mayor intensidad entre las mujeres inmigrantes que entre los hombres. De nuevo, son precisamente los colectivos con una situación económica más precaria (magrebíes, senegalesas y bolivianas) quienes refieren con más frecuencia situaciones de vulnerabilidad social (rechazo social, soledad, tristeza, separación de algún familiar). Los problemas de salud (enfermedad crónica grave) se dan principalmente entre las mujeres de la UE occidental y también entre las magrebíes.

\subsection{Integración en la CAE y proyectos de futuro}

\subsection{1. ¿Se sienten integradas con la población autóctona e inmigrante?}

En general, las mujeres inmigrantes no tienen problemas de integración, ni con la población autóctona (90\%), ni con la población inmigrante (86\%). Sin embargo, al introducir la variable nacionalidad podemos constatar cómo algunas procedencias tienen dificultades. En esta situación se encuentran sobre todo las chinas, que aproximadamente en un $60 \%$ tienen problemas de integración con la población autóctona e inmigrante; también, aunque en menor medida, las magrebíes, senegalesas y bolivianas.

\subsection{2. ¿Cuáles son sus expectativas de futuro?}

Atendiendo a las expectativas pasadas y presentes del proceso migratorio, en 2010 se ha producido un replanteamiento respecto de las intenciones al inicio del viaje. En el inicio de su proyecto migratorio, las expectativas de las mujeres se repartían de este modo: iniciar una nueva vida (36,4\%), conseguir dinero o formarse y volver a su país (35,5\%), y, como tercera opción, acompañar a un familiar $(28,1 \%)$. 


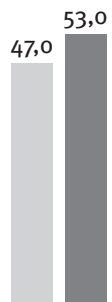

Trabajo o rentas

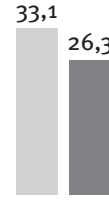

Sin ingresos

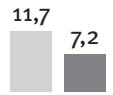

RGI

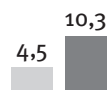

Desempleo
$1,5 \quad 0,9$

Pensión de jubilación, viudedad

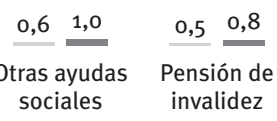

$0,3 \quad 0,3$

Pensión de alimentos
$0,4 \quad 0,1$ PNC, LISMI y similares

Mujer

Hombre

RGI: renta de garantía de ingresos. PNC: pensión no contributiva. LISMI: Ley de Integración Social del Minusválido. Fuente: Elaboración pronia a nartir de la EPIE 2010.

\section{Gráfico 3. Ranking de ingresos per cápita* de las mujeres inmigrantes, por área de origen. CAE, 2010 (€)}

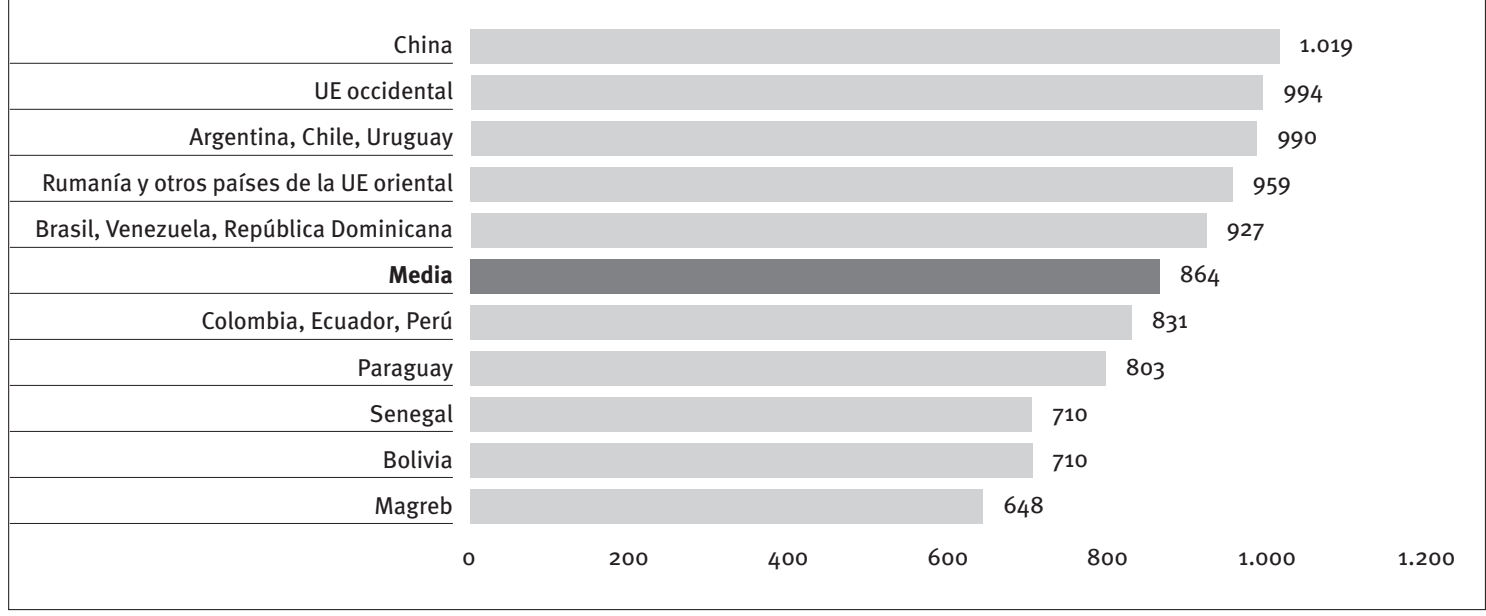

*Datos estandarizados de los ingresos del conjunto de la unidad residencial, utilizando la escala de equivalencia de Eurostat.

Fuente: Elaboración propia a partir de la EPIE 2010.

Gráfico 4. Percepción de los medios económicos en hogares inmigrantes ('desfavorecida' / 'muy desfavorecida'), por área de origen y sexo. CAE, 2010 (\%)

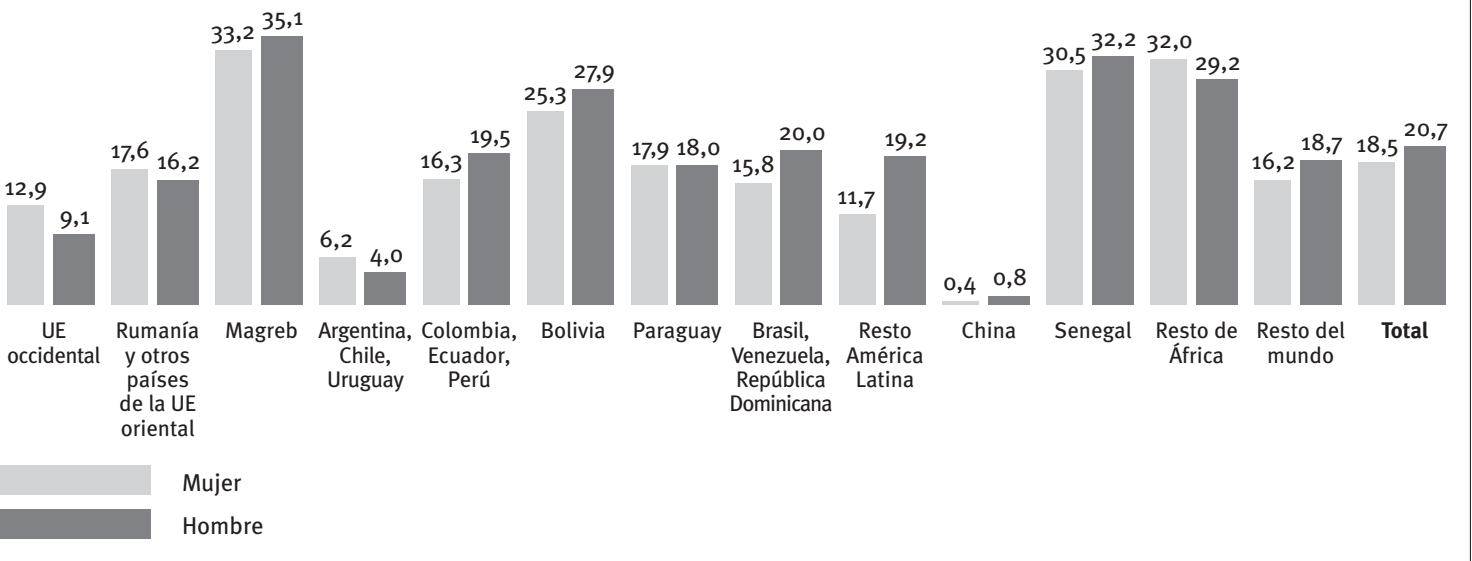

Fuente: Elaboración propia a partir de la EPIE 2010. 


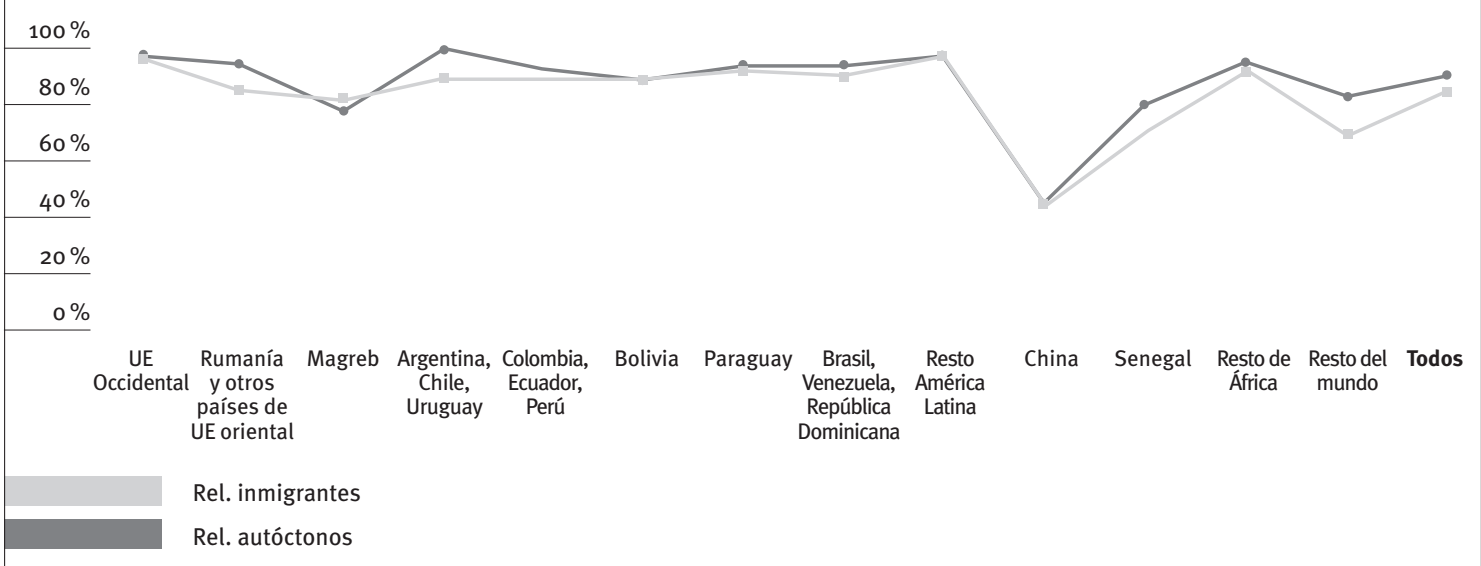

Fuente: Elaboración propia a partir de la EPIE 2010.

En 2010, año de consolidación de la crisis, las intenciones se modifican, y la mitad (49,8\%) piensa iniciar una nueva vida. Le sigue la intención de acompañar a un familiar, que se mantiene $(27,1 \%)$, y desciende (hasta un $23 \%$ ) la idea de quedarse en la CAE para conseguir dinero y volver a su país.

En cuanto a los proyectos de futuro, se les pregunta cuáles son sus intenciones y la voluntad de permanecer en la CAE en los próximos años. La gran mayoría $(88,8 \%)$ tiene intención de quedarse los próximos cinco años, y aunque estas cifras descienden (hasta el $77 \%$ ) cuando se les pregunta si se van a quedar más de ese tiempo, siguen siendo una gran mayoría las que desean continuar en la CAE. En el caso de los hombres, estos porcentajes son mayores, por término medio.

Por nacionalidades, las cifras descienden considerablemente en el caso de las paraguayas -colectivo de reciente asentamiento en la CAE- y las senegalesas -con sus dificultades sociolaborales-: sólo el $59,8 \%$ y $46 \%$, respectivamente, tienen intención de quedarse en la CAE pasados los cinco años. En el lado opuesto, destacamos la situación de las magrebíes, entre las que más de un $98 \%$ tienen intención de quedarse en la CAE en los próximos cinco años, y el $90 \%$, más de ese tiempo.

\section{Mujer y mercado laboral en el País Vasco: un acceso precario al empleo}

La situación de las mujeres inmigrantes respecto al mercado laboral en el País Vasco se caracteriza por un acceso precario al empleo; además, prácticamente la totalidad trabajan en el sector servicios (96\%) y muchas de ellas, en el sector doméstico. Aunque ésta sea la pauta general, no debemos olvidar cómo la situación laboral de las mujeres inmigrantes presenta un mapa heterogéneo, según su realidad laboral, procedencia, formación y circuns- tancias personales (Bañón, 2008). En este apartado vamos a dibujar un retrato de la situación laboral de las mujeres que están trabajando y las que están buscando empleo.

\subsection{Relación con la actividad, ocupación y paro}

Si tenemos en cuenta los datos de actividad, ocupación y paro de las mujeres inmigrantes en la CAE, lo primero que se ha de destacar es la menor tasa de paro que hay entre las mujeres, un $26,5 \%$, frente al $35 \%$ de los hombres. Muchas veces las mujeres tienen una mayor inactividad, que al final se acaba agrupando en una especie de desempleo escondido. Pero, sobre todo, los indicadores de paro, actividad y ocupación nos alertan de las posibilidades reales de integración de las mujeres extranjeras, dependiendo de su área de origen.

Teniendo en cuenta que la participación de las mujeres inmigrantes en el mercado laboral es uno de los principales factores que influyen en su proceso vital y de integración social (Aierdi et al., 2008), conocer los mecanismos de acceso y el grado de participación de las mujeres extranjeras en el mercado laboral (y la situación de la mujer desempleada en particular) a partir de las distintas procedencias nos da una fotografía nítida la situación de la mujer inmigrante en la CAE.

Por tanto, podemos establecer tres grupos claramente diferenciados atendiendo al distinto acceso al mercado laboral:

- Mujeres con un difícil acceso al mercado laboral. En este grupo se encuentran las magrebíes, con unas tasas de actividad y ocupación muy bajas; así como las senegalesas y las mujeres del resto de África, con tasas de actividad altas pero, en definitiva, con unas tasas de desempleo superiores a cualquier otra nacionalidad. Es importante destacar cómo un estancamiento de esta situa- 
Tabla 2. Indicadores generales de actividad, ocupación y paro de la población de origen extranjero, por área de origen y sexo. CAE, $2010(\%)$

\begin{tabular}{|c|c|c|c|c|c|c|c|c|c|}
\hline & \multicolumn{3}{|c|}{ Tasa de actividad } & \multicolumn{3}{|c|}{ Tasa de ocupación } & \multicolumn{3}{|c|}{ Tasa de paro } \\
\hline Área de origen & Hombre & Mujer & Total & Hombre & Mujer & Total & Hombre & Mujer & Total \\
\hline UE occidental & 85,8 & 53,9 & 72,5 & 61,8 & 35,5 & 50,8 & 27,9 & 34,1 & 29,9 \\
\hline $\begin{array}{l}\text { Rumanía y otros países de la } \\
\text { UE oriental }\end{array}$ & 90,8 & 69,9 & 80,1 & 66,8 & 48,3 & 57,3 & 26,4 & 30,1 & 28,4 \\
\hline Argentina, Chile, Uruguay & 83,3 & 69,0 & 75,9 & 62,0 & 59,9 & 60,9 & 25,6 & 13,2 & 19,8 \\
\hline Colombia, Ecuador, Perú & 80,5 & 76,0 & 77,9 & 57,5 & 60,6 & 59,2 & 28,6 & 20,2 & 24,0 \\
\hline Bolivia & 73,4 & 81,2 & 78,1 & 48,9 & 62,6 & 57,0 & 33,4 & 22,9 & 27,0 \\
\hline Paraguay & 82,8 & 89,1 & 86,7 & 53,2 & 75,1 & 66,9 & 35,7 & 15,7 & 22,9 \\
\hline $\begin{array}{l}\text { Brasil, Venezuela, República } \\
\text { Dominicana }\end{array}$ & 65,2 & 71,2 & 69,2 & 43,2 & 47,3 & 46,0 & 33,8 & 33,5 & 33,6 \\
\hline Resto de América Latina & 81,2 & 82,5 & 82,2 & 43,8 & 70,5 & 63,7 & 46,0 & 14,5 & 22,6 \\
\hline Magreb & 82,6 & 37,9 & 64,5 & 39,7 & 19,3 & 31,5 & 51,9 & 49,1 & 51,3 \\
\hline Senegal & 89,7 & 76,6 & 87,6 & 43,3 & 37,7 & 42,4 & 51,7 & 50,8 & 51,6 \\
\hline Resto de África & 77,2 & 69,8 & 73,5 & 33,7 & 25,9 & 29,8 & 56,3 & 62,9 & 59,5 \\
\hline China & 91,9 & 75,1 & 83,9 & 85,7 & 72,6 & 79,4 & 6,7 & 3,3 & 5,3 \\
\hline Resto del mundo & 92,8 & 63,3 & 77,9 & 62,0 & 48,4 & 55,2 & 33,2 & 23,5 & 29,2 \\
\hline Total & 82,9 & 68,7 & 75,5 & 53,9 & 50,5 & 52,1 & 35,0 & 26,5 & 31,0 \\
\hline
\end{tabular}

Fuente: Elaboración propia a partir de la EPIE 2010.

ción requeriría atender preferentemente al modo precario de incorporación de las mujeres de estos orígenes (Aierdi, 2012), teniendo en cuenta además que las mujeres magrebíes son el segundo colectivo más numeroso en la CAE.

- Mujeres inmigrantes con un fácil acceso al mercado laboral. La mayoría de las mujeres latinoamericanas tienen tasas de actividad muy altas, por encima de la media. Las bolivianas y paraguayas tienen tasas de actividad y ocupación superiores a la de los hombres de su misma nacionalidad.

- Mujeres con un fácil acceso al mercado laboral, entre las que prácticamente no hay paro. Ésta es la situación en la que se encuentran las chinas, con altas tasas de actividad y ocupación, y una tasa de paro prácticamente inexistente.

\subsection{Rasgos de las mujeres inmigrantes ocupadas}

En este apartado nos centramos en la posición de las mujeres extranjeras en el mercado laboral de la CAE. Analizamos los sectores en los que se emplean, el nivel de cualificación de los empleos a los que tienen acceso y los tipos de contratos. A través de estos indicadores, determinaremos el grado de integración de las mujeres inmigrantes en el mercado laboral en la CAE y sus características principales a partir de las distintas procedencias.

\subsection{1. ¿En qué sectores de actividad trabajan?}

En relación con los sectores de actividad, uno de los rasgos principales de las mujeres ocupadas en la CAE es la alta concentración que se da en un único sector de actividad, el de los servicios (96,5\%). Esta situación es diferente entre los hombres

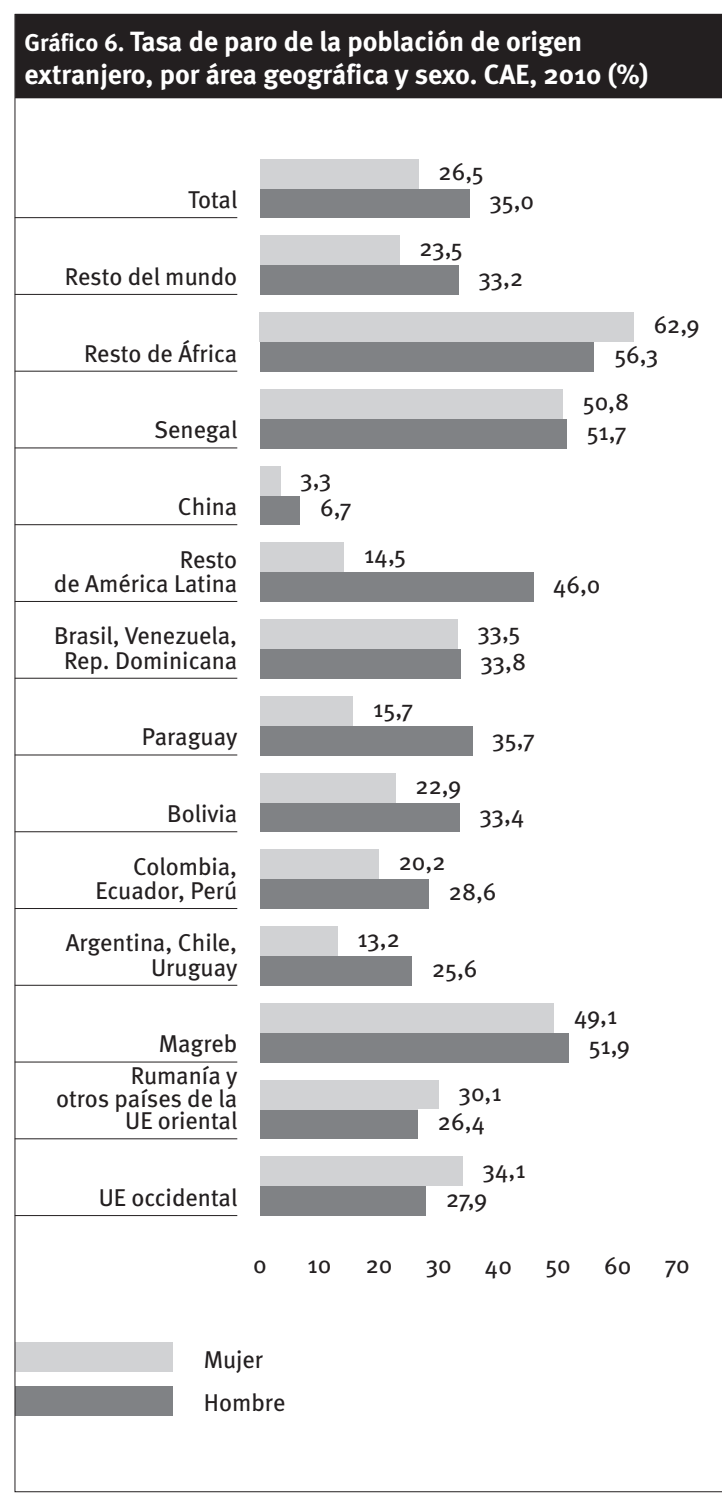

Fuente: Elaboración propia a partir de la EPIE 2010. 
Gráfico 7. Población inmigrante que trabaja, por ramas de actividad y sexo. CAE, 2010 (\%)

Servicio doméstico

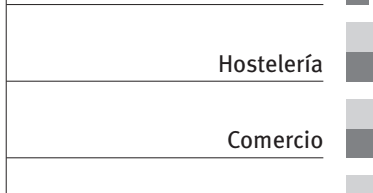

Servicios a las empresas

Educación

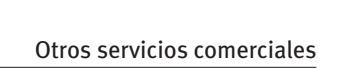

Industrias

manufactureras diversas

Material de transporte

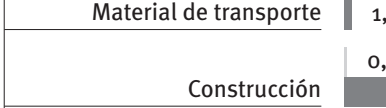

\section{0,5}

\section{0,5}

Industria de la alimentación $\quad \begin{gathered}0,5 \\ \text { I, }\end{gathered}$

\begin{tabular}{l|l} 
Transportes y comunicaciones & 0,5
\end{tabular}

\begin{tabular}{|l|l} 
Transportes y comunicaciones & \\
\hline & 0,4
\end{tabular}

Administración pública

0,8

\begin{tabular}{l|l} 
Industria otros productos $\quad 0,2$ \\
Int
\end{tabular} \begin{tabular}{l|l} 
no metálicos & 0,6
\end{tabular}

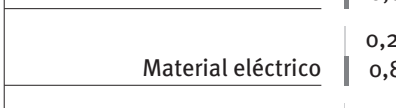

Instituciones financieras $\quad 0,0$

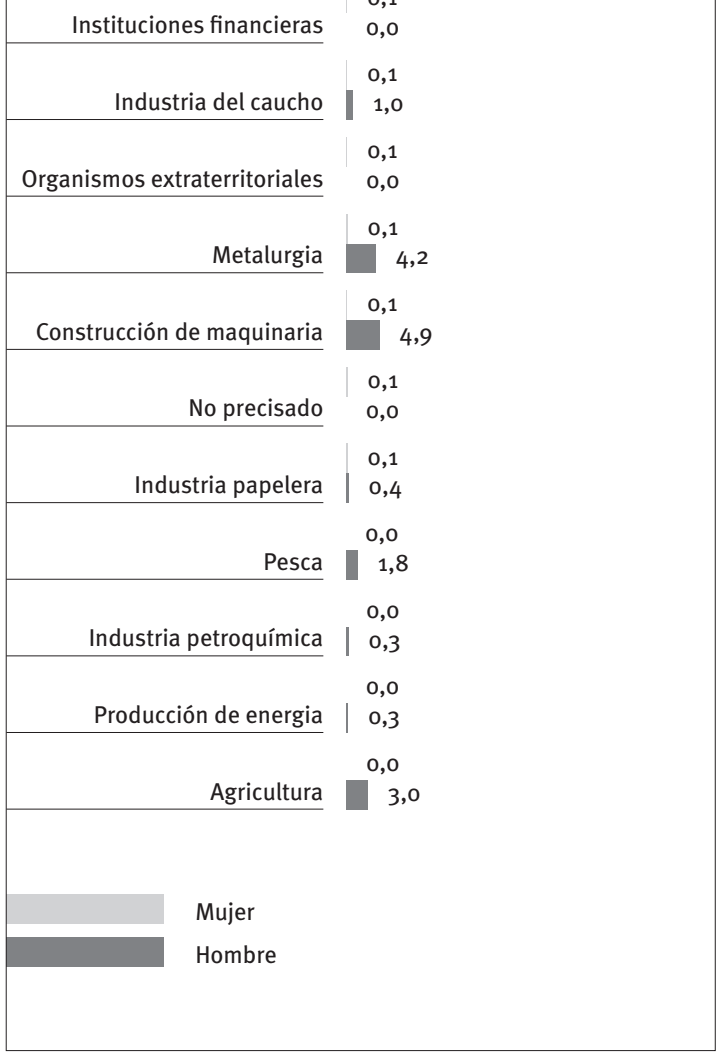

Fuente: Elaboración propia a partir de la EPIE 2010. inmigrantes, ya que sólo la mitad de ellos (48\%) trabajan en el sector servicios, y el resto se reparte entre la construcción (28\%) y la industria (18,9\%), con una minoría $(4,8 \%)$ ocupada en el sector de la agricultura y pesca. En estos sectores de actividad, en cambio, la presencia de las mujeres inmigrantes es muy escasa y se reparte entre la industria $(2,9 \%)$ y la construcción ( $0,5 \%)$; en el sector agrícola, es prácticamente inexistente.

Por tanto, vemos cómo se produce una segregación sectorial horizontal en el mercado de trabajo, donde un colectivo concreto, el de las mujeres inmigrantes, se concentra principalmente en un número relativamente pequeño de ramas de actividad y se encuentra total o parcialmente ausentes de las demás.

Gráfico 8. Mujeres inmigrantes que trabajan en las tres principales ramas de actividad, por áreas de origen. CAE, 2010 (\%)

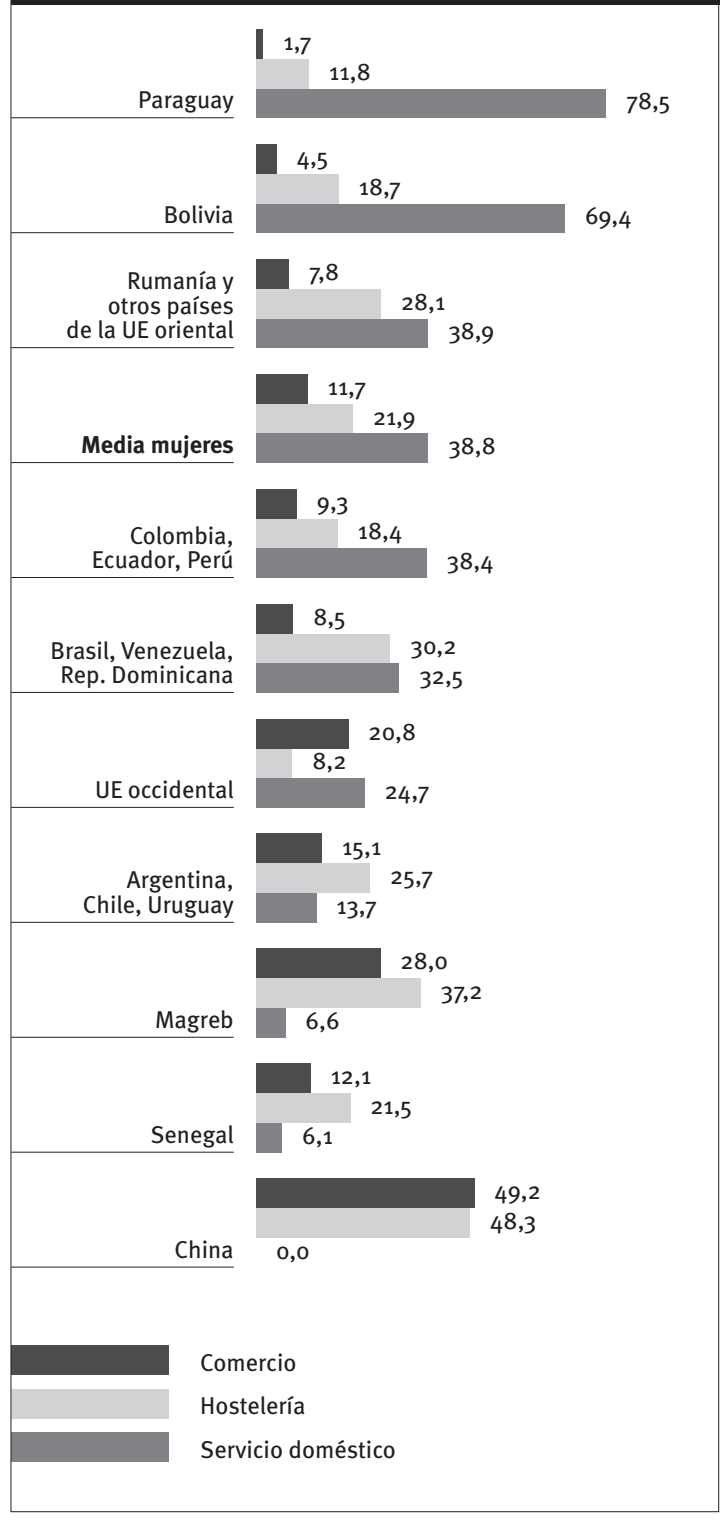

Fuente: Elaboración propia a partir de la EPIE 2010. 
El Gráfico 7, muestra la distribución de hombres y mujeres entre las distintas ramas de actividad. Tal y como se puede observar, el $72 \%$ de las mujeres se concentran en tres ramas de actividad (tareas domésticas, 38,8\%; hostelería, 21,9\%; y comercio, $11,7 \%$ ), quedando total o parcialmente ausentes de las demás. Precisamente, estos nichos laborales donde trabaja la mujer inmigrante están más desregularizados e informalizados que otros sectores de actividad económicos (Moreno et al., 2011).

Por nacionalidades, prácticamente la totalidad de las mujeres inmigrantes trabajan en el sector servicios (entre el $90 \%$ y el $100 \%$ ), a excepción de las senegalesas (48,9\%), situación que se invierte en la industria, donde esta nacionalidad supone un $43,8 \%$ frente al 2,9\% de media. Podemos observar cómo existe una relación directa entre los nichos de mercado y el origen geográfico de las personas inmigrantes, tal y como nos muestran los datos de afiliación a la Seguridad Social y otros estudios realizados. A mayor peso de la agricultura o la construcción, mayor porcentaje de varones provenientes de África o Europa; y a mayor relevancia del sector servicios, mayor peso de las latinoamericanas (Moreno et al., 2010).

\subsection{2. ¿Cuál es el nivel de cualificación de sus empleos, situación profesional y tipos de contratos?}

En relación con el nivel de cualificación de los empleos a los que tienen acceso, se detecta una segregación vertical del mercado laboral, según la cual las mujeres inmigrantes se concentran en los niveles inferiores del mercado en la escala ocupacional, con una minoría que ocupa puestos de directivas, técnicas o mandos intermedios, y una gran mayoría en trabajos sin cualificación. En concreto, un 14,1\% trabaja como directiva, técnica o mando intermedio; la gran mayoría proviene de la UE occidental y de China, y en menor medida, de Argentina, Chile y Uruguay. Por otra parte, la gran mayoría de las procedentes de Paraguay, Bolivia y Senegal que están trabajando lo hacen como trabajadoras no cualificadas.

En cuanto a la situación profesional, la gran mayoría de las mujeres ( $83 \%$ ) trabajan en el sector privado, cifra ligeramente superior a la de los hombres $(76,8 \%)$. Además sólo un $8,4 \%$ de las mujeres que trabajan lo hacen como autónomas o empresarias, porcentaje que, en el caso de los hombres, se duplica hasta el 20,5\%. Tan sólo un 3,4\% de las mujeres inmigrantes trabajan en el ámbito público. Por nacionalidades, destaca la situación de las chinas, la mitad de las cuales trabajan como empresarias o autónomas.

Si tenemos en cuenta los tipos de contrato que tienen, éstos se reparten entre los contratos indefinidos, no indefinidos y sin contrato, en ese orden. Las diferencias entre hombres y mujeres se dan, sobre todo, entre quienes trabajan sin contrato, ya que el $20,8 \%$ son mujeres, una cifra que desciende hasta el $7 \%$ en el caso de los hombres. La contratación
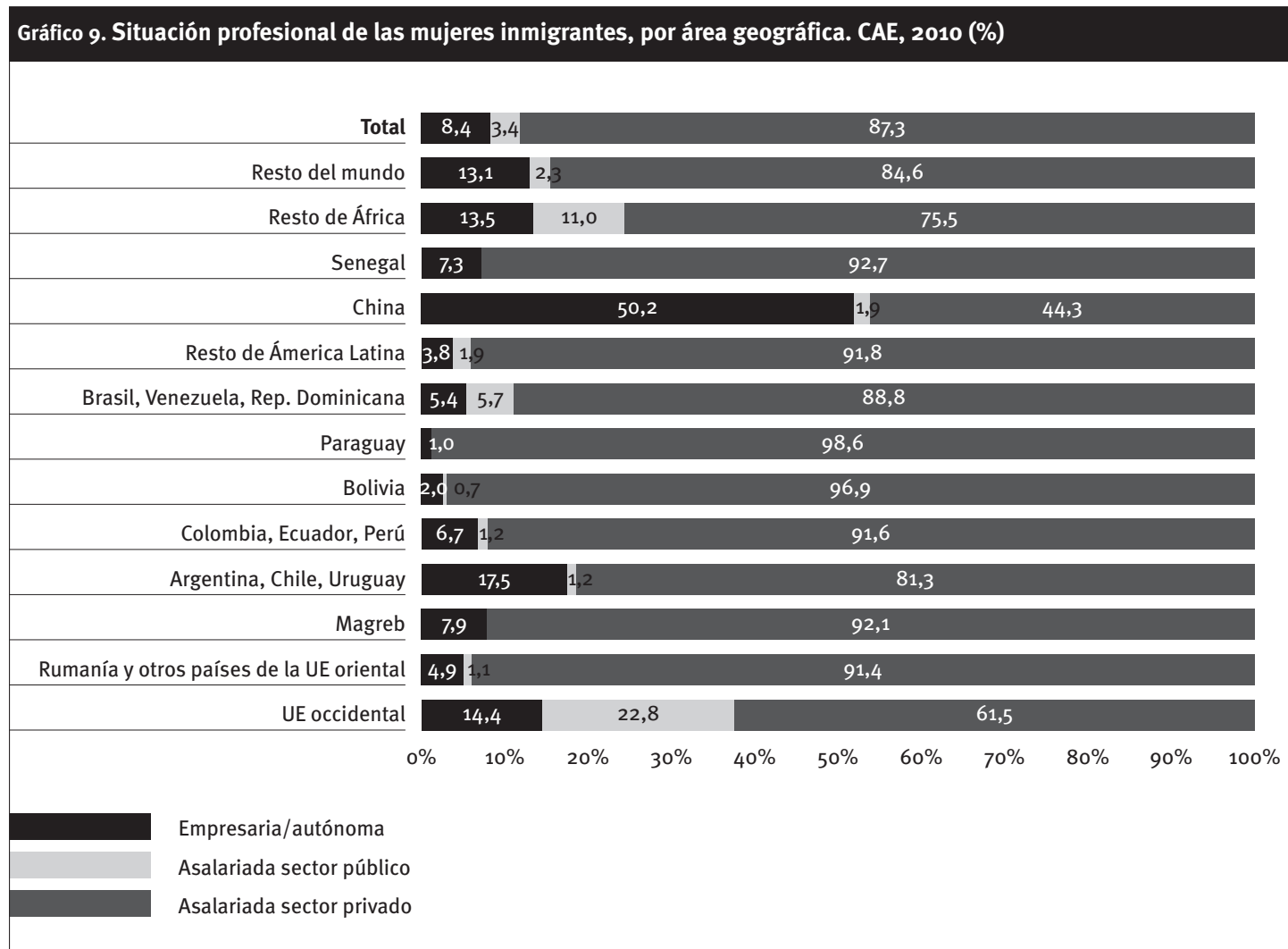
indefinida es mayor entre los hombres que entre las mujeres ( $53 \%$ frente a $44,4 \%$ ) y la contratación temporal es muy similar en ambos grupos $(25,9 \%$ frente a $27,8 \%)$.

Atendiendo a los sectores donde trabajan, su situación profesional y los tipos de contratos, podemos establecer dos grupos fundamentales:

- Acceso al mercado principalmente a través de las tareas domésticas, el cuidado de las personas dependientes y limpieza del hogar. La mayoría trabajan en el sector privado con contratos temporales o sin contrato. En este grupo se encuadra fundamentalmente la mujer latinoamericana, sobre todo la gran mayoría de las paraguayas y bolivianas, y las mujeres de Rumanía y otros países de la UE oriental.

- Acceso al mercado laboral a través del comercio y la hostelería, con poca presencia en el servicio doméstico o presencia prácticamente nula. Trabajan como autónomas o empresarias, y la gran mayoría con contratos indefinidos o temporales. En este grupo destaca la mujer china, cuyo trabajo se realiza en exclusiva entre el comercio y la hostelería.

Aunque en menor medida, en este segundo grupo se sitúan también las mujeres africanas, con muy poca presencia en el ámbito doméstico y comercio, y algo más en el sector de la hostelería, con cifras por encima de la media. Igualmente, hay una presencia importante de mujeres procedentes de Rumanía y otros países de la UE oriental, Brasil, Venezuela y República Dominicana, así como de Argentina, Chile y Uruguay.

Si nos fijamos en las personas que trabajan en el sector servicios y sin contrato, se observa una polarización entre nacionalidades y sexo. Por una parte, se encuentran las paraguayas, bolivianas, rumanas y otras mujeres de la UE oriental, que en un alto porcentaje trabajan en el sector servicios sin contrato. En el lado opuesto, están las argentinas, chilenas y uruguayas, así como las chinas y magrebíes, colectivos donde el porcentaje de mujeres que trabajan sin contrato está por debajo de la media.

\subsubsection{Algunos indicadores complementarios}

Con independencia de los sectores donde estén trabajando las mujeres inmigrantes, otros datos laborales reseñables, relativos a las mujeres ocupadas de origen extranjero, nos vuelven a poner de manifiesto la polarización que se da en el mercado laboral también entre las mujeres de distintas áreas de origen:

- Un 20,7\% desarrolla su actividad sin afiliación a la Seguridad Social. Sobre todo son las paraguayas $(42,6 \%)$ y bolivianas $(25,8 \%)$, seguidas de las rumanas y otras mujeres de la UE oriental las que se encuentran en esta situación.

Gráfico 10. Mujeres inmigrantes por área geográfica y tipo de contrato más habitual. CAE, $2010(\%)$

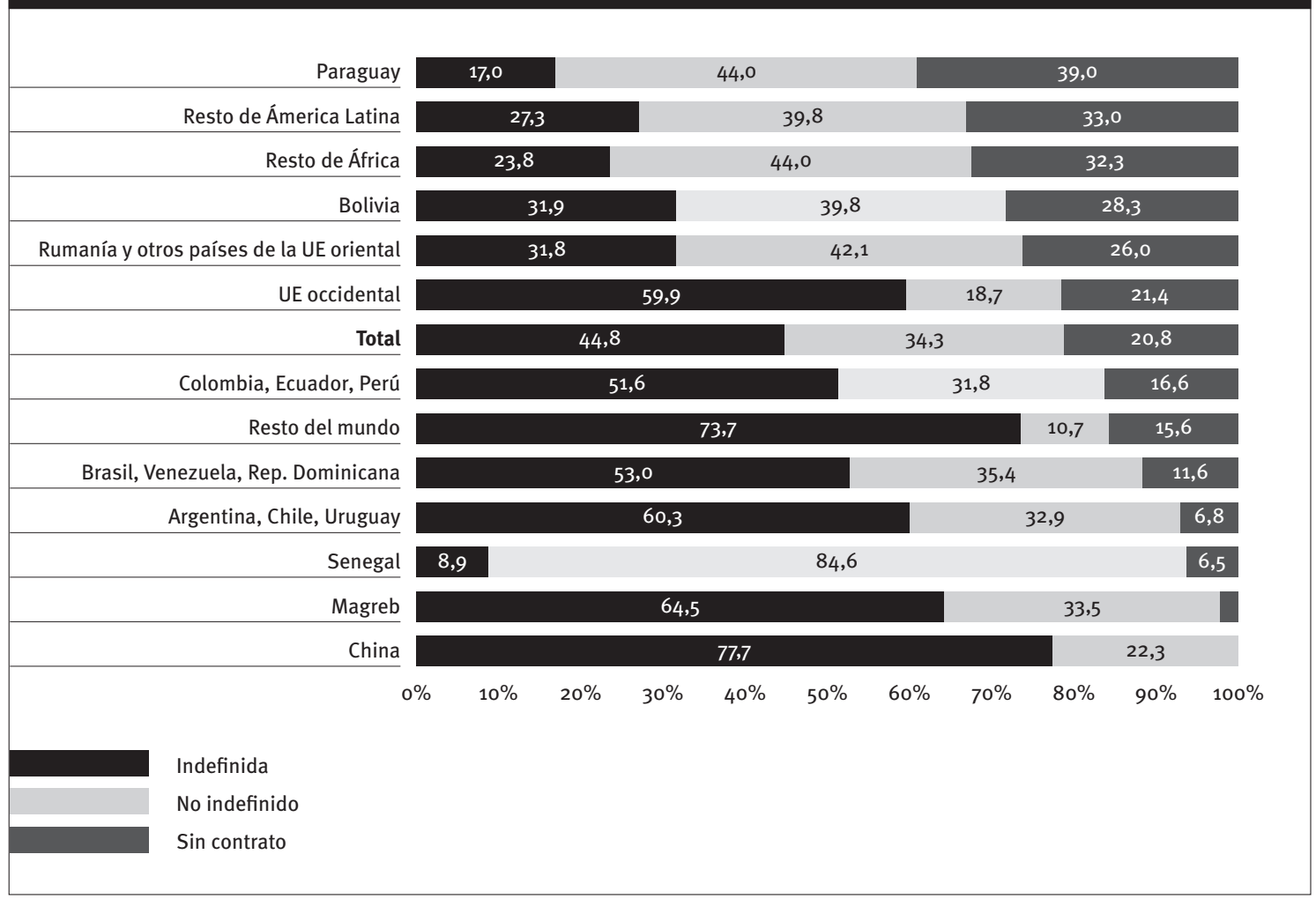

Fuente: Elaboración propia a partir de la EPIE 2010. 


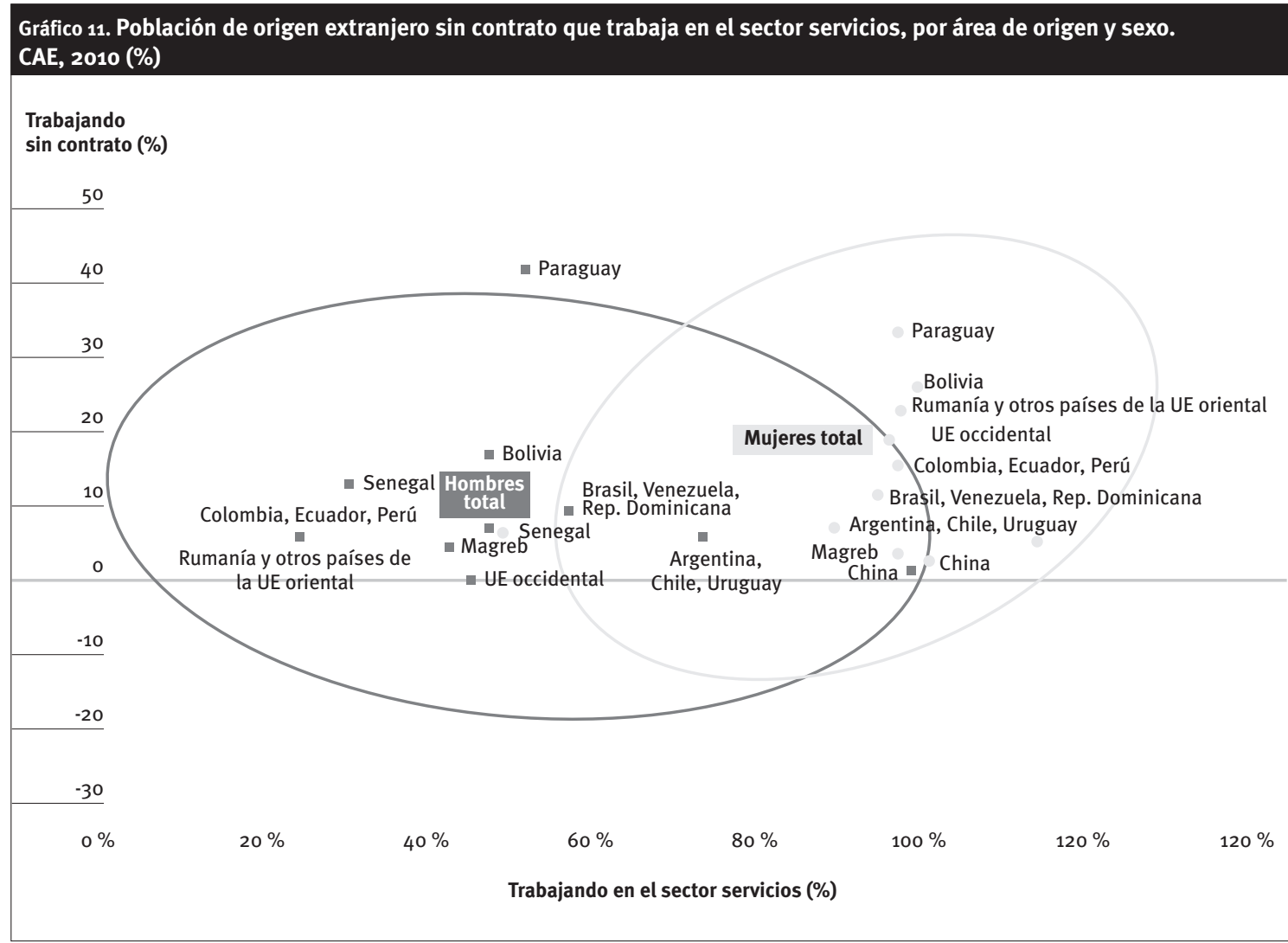

Fuente: Elaboración propia a partir de la EPIE 2010.

- Un 10,6\% de las mujeres ocupadas de origen extranjero están pluriempleadas. Esta situación tiene mayor prevalencia entre las mujeres originarias de Paraguay (18,1\%), y también en Colombia, Ecuador y Perú (17,1\%), que presentan cifras por encima de la media.

- La mitad de las mujeres que están trabajando dedican a esta actividad entre 30 y 45 horas semanales. La gran mayoría, más del $60 \%$, procede de la UE occidental, y de Argentina, Chile y Uruguay. El resto se reparte entre un 31,4\% que trabaja menos de 30 horas y un $18,9 \%$ que trabaja más de 45 horas semanales. En este último grupo, sobresalen las chinas (aproximadamente 6 de cada 10) y, en menor medida, las provenientes de Magreb y Senegal.

\subsection{Situación de la mujer desempleada}

En este apartado analizamos la situación de las mujeres inmigrantes desempleadas. Para ello, hemos utilizado tres preguntas del cuestionario relativas al tiempo de búsqueda de empleo, los mecanismos más utilizados en la búsqueda y los obstáculos más habituales con los que se encuentran estas mujeres.

\subsection{1. ¿Cuánto tiempo llevan buscando empleo?}

En 2010, año de consolidación de la crisis, el $26,5 \%$ de las mujeres inmigrantes están en paro y el $64 \%$ lleva buscando empleo menos de 12 meses. En esa fecha, son las mujeres de procedencia africana, en concreto las magrebíes y subsaharianas, las que sufren situaciones de paro de larga duración por encima de la media y un difícil acceso al mercado de trabajo en la CAE.

\subsection{2. ¿Cuáles son las estrategias más utilizadas en la búsqueda de empleo?}

En ese año, las estrategias de búsqueda de empleo se centran principalmente en el Servicio Público de Empleo Estatal (SEPE) y el Servicio Vasco de empleo Lanbide, sin darse diferencias significativas entre hombres y mujeres inmigrantes desempleados.

Sin embargo, cuando analizamos otras estrategias de búsqueda de empleo encontramos algunos matices: las mujeres utilizan más las asociaciones, la mediación institucional (ayuntamiento) y las empresas de trabajo temporal, mientras que los hombres recurren más a la ayuda familiar o de amistades, así como al contacto con empresas o anuncios de ofertas de 


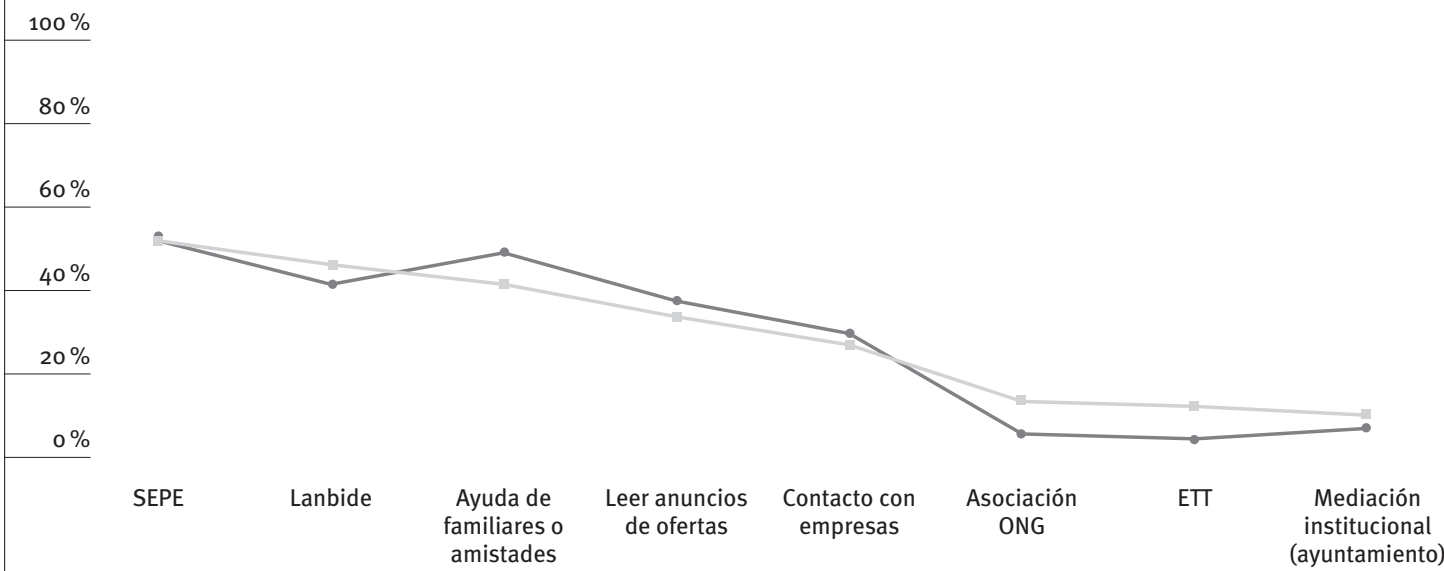

trabajo. De hecho, para algunas nacionalidades ésta se convierte en la principal estrategia, como sucede entre las paraguayas, rumanas y mujeres de la UE oriental, o las senegalesas, donde entre el $64 \%$ y el $72 \%$ elige esta opción.

Otra estrategia para buscar empleo es el seguimiento de anuncios de ofertas de trabajo, utilizado por el $34,1 \%$ de mujeres inmigrantes $y$, en concreto, el mecanismo más usado por las argentinas, chilenas y uruguayas $(62,2 \%)$. Como podemos comprobar a través de diversos estudios (loé, 2001), suelen ser los autóctonos quienes más utilizan este recurso.

Por otro lado, el $27,5 \%$ de las mujeres contactan directamente con las empresas para buscar trabajo. Este mecanismo lo utilizan sobre todo senegalesas $(48,8 \%)$, bolivianas $(38,8 \%)$ y mujeres de la UE occidental (36\%).

Las ONG, las ETT y la mediación institucional (ayuntamientos) son mecanismos menos utilizados por las mujeres inmigrantes: sólo una de cada diez usa alguna de estas opciones para la búsqueda de empleo. En concreto, las ONG son utilizadas por el $13,5 \%$ de las mujeres inmigrantes. La búsqueda de empleo a través de las ETT es usada por el 12,6\% de las mujeres inmigrantes. En este caso, las empresas de trabajo temporal es un recurso bastante habitual entre las chinas: un 40,2\% lo utiliza. También podemos destacar, aunque en menor medida, su uso torianas y peruanas (15,6\%), y las paraguayas (13,9\%). La mediación institucional (ayuntamiento) es la vía menos utilizada por las mujeres en general $(10,1 \%) ;$ sólo las magrebíes usan algo más este recurso $(15,8 \%)$.

\subsection{3. ¿Cuáles son los obstáculos más habituales para encontrar un empleo?}

La mayoría las mujeres inmigrantes desempleadas señalan diversos obstáculos para encontrar un empleo, sobre todo la falta de cualificación y de experiencia laboral. Unido a ella, dos de cada diez indican el nivel de conocimiento de los idiomas locales como principal obstáculo para la inserción laboral. También es importante destacar cómo las cargas familiares son una traba: el 16,7\% de ellas lo consideran así, siendo el tercer obstáculo a la hora de acceder a un empleo.

Como es conocido, los factores mencionados ejercen el mismo tipo de influencia negativa en las posibilidades de acceso al empleo de las mujeres paradas autóctonas. Hay, sin embargo, dos limitaciones que resultan propias de la población de origen extranjero: una es la situación administrativa o legal, y otra, el país de procedencia.

- Respecto a la situación administrativa o legal, hay que considerar que un $9,7 \%$ de las mujeres que están en situación de desempleo se encuentran con este obstáculo. Además, algunas tasas por nacionalidad nos alertan de las dificultades de inserción de las mujeres inmigrantes por este motivo, sobre todo de las senegalesas (44,8\%) y las paraguayas (41,6\%).

- La segunda limitación propia de la población de origen extranjero es el país de procedencia. Así opina el 7,7\% de las mujeres inmigrantes, pero sobre todo las senegalesas (16,8\%), las magrebíes $(15,5 \%)$ y las paraguayas $(13,2 \%)$. 


$$
\begin{aligned}
& \text { - falta de cualificación } \\
& \text { - experiencia laboral } \\
& \text { - conocimiento de idiomas } \\
& \text { - cargas familiares }
\end{aligned}
$$

Hay otros problemas que, aunque con menor incidencia de cara a encontrar un empleo entre las mujeres inmigrantes en general, sí son importantes para determinadas nacionalidades. Así, la edad es el principal obstáculo mencionado por las procedentes de Argentina, Chile y Uruguay.

En definitiva, aunque hay una serie de dificultades asociadas a ser mujer y de origen extranjero, vemos cómo los problemas principales son los mismos de la población autóctona, y que son las nacionalidades las que nos aclaran las distintas posibilidades que tienen las mujeres inmigrantes a la hora de integrarse en el mercado laboral. A modo de ejemplo, podemos ver aquí la relación de mujeres inmigrantes por nacionalidades y principales problemas:

- La situación legal como obstáculo se hace patente entre las provenientes de Paraguay $(41,1 \%)$ y Senegal (44,8\%).

- La experiencia laboral, cargas familiares y nivel de instrucción son los obstáculos más habituales para las mujeres de la UE occidental.

- El idioma (27,7\%) y la experiencia laboral (23,3\%) son los principales problemas para las rumanas y las mujeres de otros países de la UE oriental.

- Las dificultades de las magrebíes están relacionadas sobre todo con el idioma, la experiencia laboral y el país de origen.

- Las trabas de las argentinas, chilenas y uruguayas se vinculan con la edad.

- Para las colombianas, ecuatorianas y peruanas, el obstáculo principal es el nivel de instrucción.

Estas dificultades colocan a la mujer inmigrante en una situación de vulnerabilidad social, al margen de los rasgos individuales, tal y como muestran los resultados del estudio, así como de otras investigaciones realizadas donde se plantea esta misma situación. Es decir, que por el hecho de ser mujer y de origen extranjero, las mujeres inmigrantes están expuestas a una mayor vulnerabilidad social (Parella, 2006).
3.4. Experiencia laboral de las mujeres inmigrantes: acceso al mercado de trabajo, experiencia en el último año, grado de satisfacción

La experiencia laboral de las mujeres inmigrantes en la CAE la analizamos a partir de la percepción que tienen sobre el acceso al mercado de trabajo, los problemas relacionados con el trabajo y su grado de satisfacción, teniendo en cuenta las distintas procedencias.

\subsection{1. ¿Cómo es el acceso al mercado de trabajo?}

En el acceso al mercado de trabajo se preguntan dos cuestiones: por una parte, si las mujeres inmigrantes pueden acceder a todo tipo de empleos; $y$, por otra, los trabajos por los que han pasado en el último año.

- Entre las mujeres inmigrantes que están en la CAE en edad de trabajar, la gran mayoría $(77,1 \%)$ manifiesta poder acceder a todo tipo de empleos, sin limitación. Sin embargo, al analizar la tasa de accesibilidad al empleo por áreas de origen, comprendemos las posibilidades reales de acceso de las mujeres extranjeras: alrededor de 4 de cada 10 mujeres magrebíes y senegalesas, así como las paraguayas, tienen problemas para acceder a todo tipo de empleos. Entre las razones que podrían explicar esta situación, en el caso de las magrebíes, estarían los motivos culturales; en el caso de las senegalesas y paraguayas, sobre todo se podría explicar por su situación administrativa actual, con un alto número de personas en situación administrativa irregular.

- El 84,1\% de las mujeres inmigrantes con experiencia de trabajo en Euskadi han tenido contacto con el empleo en algún momento del último año. Un $68 \%$ ha ocupado un único empleo en los últimos doce meses y un $15,5 \%$ de las que han trabajado han tenido dos o tres empleos. Sólo el $0,9 \%$ han pasado por más de cuatro empleos.

A pesar del alto porcentaje que han tenido un empleo en este último año, algunas tasas por origen nos 
aclaran con mayor nitidez qué mujeres inmigrantes tienen mayor movilidad laboral; tal es el caso de las latinoamericanas y, concretamente, de las colombianas, las ecuatorianas y las peruanas, así como de las paraguayas, las bolivianas, y también de las rumanas y de la UE oriental.

\subsection{2. ¿Cuáles son los problemas más habituales?}

Los problemas más habituales con los que se enfrentan, o se han enfrentado, las mujeres inmigrantes en el último año en su experiencia laboral son los siguientes:

- El primer problema es el relativo a la obligación de trabajar horas extraordinarias, sobre todo en el caso de las senegalesas, paraguayas y mujeres de la UE occidental.

- El segundo problema se refiere a la jornada de trabajo mayor que la habitual. Aquí, nuevamente, el colectivo más afectado son las paraguayas, bolivianas y magrebíes.

- El tercer problema está referido a una remuneración inferior a la del resto de las personas que ocupan el mismo puesto, sobre todo para las bolivianas y paraguayas.

A través de los problemas que se dan en el trabajo, podemos establecer varios perfiles, que confirman las distintas formas de acceso al mercado laboral entre las mujeres inmigrantes de distintas nacionalidades; para ello, destacamos las problemáticas que están por encima de la media:

- Entre las de la UE occidental, los problemas principales se centran en aspectos relacionados con la obligación de trabajar horas extraordinarias o con un salario menor que el contrato habitual.

- Entre las provenientes de Rumanía u otros países de la UE oriental, dos dificultades sobresalen por encima de la media: estar relegadas a las peores tareas por ser extranjeras y trabajar en situación irregular por expreso deseo del empresario.

- Para las magrebíes, los principales problemas en el trabajo están relacionados con tener una jornada mayor que la habitual y estar obligadas a hacer horas extraordinarias.

- Las originarias de Argentina, Chile y Uruguay se refieren a la dificultad de tener una jornada mayor que la habitual, y a la incompatibilidad para cuidar a sus hijos e hijas.

- Entre las colombianas, peruanas y ecuatorianas los problemas están relacionados con una jornada laboral mayor que la habitual, con trabajar en situación irregular por expreso deseo del empresario y con la incompatibilidad de cuidar a sus hijos e hijas.

A pesar de las situaciones problemáticas detectadas por las mujeres inmigrantes en su trabajo, predomina la valoración positiva de las condiciones laborales: más de ocho de cada diez mujeres entrevistadas están satisfechas con la relación con jefes/superiores, las condiciones materiales, el ajuste a su cultura y religión, el nivel de riesgos, el ritmo de actividad y el horario. Sin embargo, menos de la mitad se sienten satisfechas con las posibilidades de promoción, siendo éste el aspecto peor valorado. Si comparamos las valoraciones realizadas por la población extranjera a este respecto, se constata que son mucho más bajas entre las mujeres inmigrantes que entre los hombres, con trece puntos de diferencia.

\section{Conclusiones y reflexiones finales}

Para concluir este artículo, vamos a subrayar algunas de las principales características de la mujer inmigrante y de su relación con el mercado laboral. En primer lugar, debemos subrayar que la variable que más discrimina con respecto a la población inmigrante no es tanto el sexo como el país de procedencia. Unida a esta variable, la situación administrativa y el tiempo de estancia en el País Vasco tienen una gran relevancia también. Aunque es cierto que éstas son las variables que más influyen en las diferencias entre población inmigrante, cuando analizamos la situación de las mujeres inmigrantes y cómo se están integrando en el mercado laboral, se encuentran similitudes con las divergencias que se dan en la población autóctona por sexo, y que, en varias dimensiones, se acentúan en el caso de la mujer inmigrante.

A continuación, presentamos una tipología con varios grupos de mujeres inmigrantes residentes en la CAE, según su grado de integración económica y social:

- Integración social alta e integración laboral alta: mujeres provenientes de la UE occidental o países como Argentina, Chile o Uruguay. Aunque su peso no es muy alto en el País Vasco, es el colectivo de mujeres que muestra mejores indicadores de integración social y económica, y de integración con la población autóctona.

- Integración social media e integración laboral alta (sector servicios): son mujeres provenientes de Colombia, Ecuador y Perú, con un alto acceso al mercado laboral, que se vertebra sobre todo a través de las tareas domésticas y, en menor medida, de la hostelería. Las colombianas y ecuatorianas presentan unos indicadores de integración mayor, debido a una estancia más larga y a una mejor situación administrativa.

Las bolivianas y, sobre todo, las paraguayas tienen peores indicadores de integración, porque llevan menos tiempo entre nosotros, y por tanto, tienen una situación administrativa más precaria.

- Integración social baja e integración laboral baja: destacamos el colectivo de mujeres africanas, que muestra unos indicadores de integración relativamente bajos, y un alto grado de precariedad y vulnerabilidad social. Los índices de actividad y ocupación son sensiblemente menores que el 
Tabla 3. Mujeres de origen extranjero con experiencia de trabajo en Euskadi, por situaciones problemáticas vividas* y área geográfica de origen. CAE, 2010 (\%)

\begin{tabular}{|c|c|c|c|c|c|c|c|c|c|c|c|c|c|c|c|}
\hline \multirow{2}{*}{\multicolumn{2}{|c|}{$\begin{array}{l}\text { Situaciones problemáticas en el } \\
\text { trabajo }\end{array}$}} & \multicolumn{13}{|c|}{ Áreas de origen } & \multirow{3}{*}{$\begin{array}{l}\text { Total } \\
10,9\end{array}$} \\
\hline & & \multirow{2}{*}{$\frac{A}{18,3}$} & \multirow{2}{*}{$\frac{\text { B }}{6,6}$} & \multirow{2}{*}{$\frac{\mathrm{C}}{10,6}$} & \multirow{2}{*}{$\frac{\text { D }}{3,8}$} & \multirow{2}{*}{$\frac{E}{6,2}$} & \multirow{2}{*}{$\frac{F}{14,9}$} & \multirow{2}{*}{$\frac{\mathbf{G}}{21,2}$} & \multirow{2}{*}{$\frac{H}{10,2}$} & \multirow{2}{*}{$\frac{\text { I }}{8,7}$} & \multirow{2}{*}{$\frac{J}{11,3}$} & \multirow{2}{*}{$\frac{K}{25,3}$} & \multirow{2}{*}{$\frac{\mathbf{L}}{9,6}$} & \multirow{2}{*}{$\frac{M}{20,4}$} & \\
\hline $1^{0}$ & $\begin{array}{l}\text { Obligación de hacer horas } \\
\text { extraordinarias }\end{array}$ & & & & & & & & & & & & & & \\
\hline $2^{0}$ & $\begin{array}{l}\text { Jornada de trabajo mayor } \\
\text { que la habitual }\end{array}$ & 1,0 & 6,7 & 13,0 & 8,3 & 11,7 & 16,4 & 16,0 & 9,0 & 12,1 & 2,3 & 0,0 & 9,6 & 14,4 & 10,2 \\
\hline $3^{0}$ & $\begin{array}{l}\text { Salario menor que el } \\
\text { de otras personas en el } \\
\text { mismo puesto }\end{array}$ & 3,2 & 4,8 & 4,5 & 2,2 & 7,7 & 16,4 & 10,0 & 6,4 & 8,6 & 6,1 & 0,0 & 6,0 & 12,0 & 7,5 \\
\hline $4^{0}$ & $\begin{array}{l}\text { Trabajo en situación } \\
\text { irregular por deseo del } \\
\text { empresario }\end{array}$ & 7,0 & 9,3 & 0,0 & 2,1 & 10,7 & 7,6 & 9,4 & 4,7 & 4,2 & 0,0 & 0,0 & 0,0 & 1,1 & 6,5 \\
\hline $5^{0}$ & $\begin{array}{l}\text { Incompatibilidad para } \\
\text { cuidar hijos e hijas }\end{array}$ & 4,4 & 5,7 & 6,1 & 6,9 & 8,0 & 9,3 & 9,5 & 5,9 & 1,8 & 5,3 & 0,0 & 4,8 & 3,8 & 6,2 \\
\hline 60 & $\begin{array}{l}\text { Salario menor que el del } \\
\text { contrato o el habitual }\end{array}$ & 8,2 & 4,8 & 4,5 & 0,2 & 0,7 & 8,6 & 10,8 & 3,8 & 5,5 & 0,0 & 13,9 & 0,0 & 12,0 & 4,7 \\
\hline $7^{0}$ & $\begin{array}{l}\text { Relegada a las peores } \\
\text { tareas por ser extranjera }\end{array}$ & 0,0 & 9,8 & 3,3 & 0,7 & 4,4 & 9,2 & 5,1 & 2,2 & 0,0 & 0,0 & 0,0 & 0,0 & 0,0 & 3,6 \\
\hline $8^{\circ}$ & $\begin{array}{l}\text { Trato humillante por } \\
\text { empleadores o superiores }\end{array}$ & 0,1 & 2,1 & 4,5 & 1,0 & 3,5 & 5,2 & 6,1 & 5,8 & 7,2 & 0,0 & 4,0 & 6,0 & 0,0 & 3,6 \\
\hline $9^{0}$ & $\begin{array}{l}\text { Imposibilidad de ascenso } \\
\text { en la empresa por ser } \\
\text { extranjera }\end{array}$ & 1,6 & 2,3 & 0,0 & 1,2 & 3,8 & 7,8 & 4,2 & 3,7 & 4,7 & 2,0 & 0,0 & 0,0 & 4,4 & 3,5 \\
\hline $10^{\circ}$ & $\begin{array}{l}\text { Imposibilidad de asumir } \\
\text { responsabilidades por ser } \\
\text { extranjera }\end{array}$ & 0,3 & 2,4 & 0,0 & 0,0 & 3,6 & 5,3 & 4,3 & 4,2 & 0,0 & 0,0 & 4,0 & 0,0 & 4,4 & 2,6 \\
\hline $11^{0}$ & $\begin{array}{l}\text { Jornada de trabajo menor } \\
\text { que la del contrato } \\
\text { habitual }\end{array}$ & 8,2 & 0,0 & 0,0 & 4,0 & 1,0 & 6,3 & 2,7 & 3,9 & 1,4 & 0,0 & 0,0 & 0,0 & 0,0 & 2,6 \\
\hline $12^{0}$ & $\begin{array}{l}\text { Aislamiento social o } \\
\text { rechazo por parte de } \\
\text { compañeros de trabajo }\end{array}$ & 0,5 & 1,6 & 4,5 & 2,8 & 2,5 & 1,3 & 1,2 & 3,4 & 6,4 & 0,0 & 11,7 & 0,0 & 1,7 & 2,4 \\
\hline $13^{0}$ & $\begin{array}{l}\text { Salario mayor que el } \\
\text { contrato habitual }\end{array}$ & 0,0 & 1,3 & 0,0 & 2,2 & 3,6 & 4,3 & 1,7 & 1,2 & 5,4 & 0,0 & 0,0 & 0,0 & 0,0 & 2,2 \\
\hline $14^{\circ}$ & $\begin{array}{l}\text { Menores niveles de } \\
\text { seguridad en el trabajo }\end{array}$ & 0,0 & 2,9 & 0,0 & 0,2 & 2,3 & 5,6 & 0,9 & 3,6 & 0,0 & 4,6 & 0,0 & 0,0 & 0,0 & 2,0 \\
\hline
\end{tabular}

* Respuestas a las preguntas 66-79 del cuestionario: “Se da o ha dado alguna de las siguientes situaciones en su trabajo o en los que ha tenido?’.

A: UE occidental. B: Rumanía y otros países de la UE oriental. C: Magreb. D: Argentina, Chile y Uruguay. E: Colombia, Ecuador y Perú. F: Bolivia. G: Paraguay. H: Brasil, Venezuela, República Dominicana. I: Resto de América Latina. J: China. K: Senegal, L: Resto de África. M: Resto del mundo.

Fuente: Elaboración propia a partir de la EPIE 2010.

resto, a la par que declaran un menor nivel educativo, una mayor discriminación percibida y una menor interacción con las personas autóctonas. En este grupo, la situación en la que se encuentra la mujer senegalesa es muy precaria, ya que, a las dificultades que hemos comentado, se les suma la alta tasa de irregularidad, que, como ya se ha mencionado, afecta a la integración del colectivo. Nótese que el de mujeres africanas es el segundo colectivo más importante en el País Vasco, por detrás del latinoamericano.

- Integración social baja e integración laboral alta: en este grupo se encuentran las chinas, con una alta inserción laboral, una buena integración económica, pero con una escasa interacción con la población autóctona. En todo caso, es un colectivo minoritario dentro del conjunto de mujeres inmigrantes.

Junto a esta tipología, también pueden subrayarse tres aspectos sobre la inserción laboral de la mujer inmigrante en el País Vasco:
- Relevancia del sector servicios.

- Precariedad en el empleo.

- Prevalencia de la mujer latinoamericana en relación a la estructura socioeconómica y demográfica del País Vasco.

\subsection{La relevancia del sector servicios}

El $96 \%$ de las mujeres inmigrantes en el País Vasco que están trabajando lo hacen en el sector servicios, y es el subsector de las tareas domésticas el más relevante. Si tenemos en cuenta las distintas nacionalidades, las latinoamericanas se sitúan mayoritariamente en el subsector de las tareas domésticas y muestran unas tasas de ocupación más altas que las de otras procedencias, y también unas tasas de paro menores. La inserción en el mercado laboral para el colectivo latinoamericano es más fácil y fluida que para otras nacionalidades, como por ejemplo, las africanas, o incluso para las provenientes de la Rumanía y otras de la UE oriental. 
La mayor inserción laboral hace que los ingresos económicos de las mujeres latinoamericanas sean mayores que los de los hombres de esa misma nacionalidad, como sucede en el caso boliviano y paraguayo. Todo ello indica un mayor empoderamiento de la mujer latinoamericana. No debemos olvidar que el inicio del proyecto migratorio en este colectivo es de la mujer y no del hombre. Lo contrario sucede en el colectivo africano, donde la mujer tiene una situación más precaria, un menor acceso laboral, y una dependencia económica y social mucho mayor con respecto a los hombres.

\subsection{Precariedad en el empleo}

El mayor acomodo en el mercado laboral de la mujer inmigrante se da a costa de unas condiciones laborales relativamente precarias y, en general, peores que las de los hombres inmigrantes, como hemos podido constatar en el artículo: mayor tasa de empleo sin contrato, peores condiciones de contrato, ingresos menores. Respecto a las mujeres inmigrantes, se observan algunas diferencias:

- Segregación laboral horizontal, concentrándose la gran mayoría en un único sector de empleo, el de servicios.

- Discriminación indirecta que se establece desde el propio mercado y deriva en una entrada mayoritaria de las mujeres al trabajo en el ámbito doméstico.

- Dualización en el empleo, referido a las categorías profesionales y su relación con las distintas procedencias de las mujeres inmigrantes. Por una parte, los puestos cualificados son ocupados por mujeres provenientes de la UE occidental, Argentina, Chile, Uruguay y China, frente a las del resto de orígenes geográficos, que ocupan mayoritariamente trabajos no cualificados.

\subsection{Prevalencia de la mujer latinoamericana en relación a la estructura socioeconómica y demográfica del País Vasco}

La inmigración en el País Vasco tiene cara de mujer, de mujer latinoamericana. Así, emerge un modelo de inserción laboral precaria de la mujer inmigrante en el sector de las tareas domésticas y los cuidados personales que va a ser uno de los ejes para el mantenimiento de las cotas de bienestar actual de la población autóctona, dando respuesta a elementos como la dependencia, el mantenimiento de la estructura demográfica laboral o el acceso de la mujer autóctona al mercado laboral. Dicho de otro modo, parece que se ha optado por un modelo migratorio en el que el bienestar de la mayoría - población autóctona- va a sustentarse en la vulnerabilidad y la precariedad de una minoría, caracterizada en gran parte por el colectivo inmigrante, y muy especialmente por la mujer inmigrante.

\subsection{Prospectiva}

De cara al futuro, creemos que esta pauta migratoria va a afianzarse y que va a ser el modelo prevalente en los próximos años en el País Vasco. Más aún, este modelo puede ser la avanzadilla de algunas tendencias que pueden generalizarse en otros países y regiones de Europa. 


\section{Referencias bibliográficas}

AIERDI, X. (2012): Informe socioeconómico de la C.A. de Euskadi 2012, Eustat.

AIERDI, X. et al. (2008): Población latinoamericana en la CAE 2007, Bilbao, Ikuspegi-Observatorio Vasco de Inmigración.

BAÑóN, A. (2008): Comunicación, empleo y mujer inmigrante, Donostia-San Sebastian, Tercera Prensa.

GOBIERNO VASCO (2011): Encuesta de la Población Inmigrante Extranjera Residente en la Comunidad Autónoma de Euskadi, Vitoria-Gasteiz, Gobierno Vasco.

HIDALGO, Á.; CALDERÓN, M. J.; y PÉREZ, S. (2006): La discriminación salarial y segregación laboral de los inmigrantes. Identificación de espacios laborales prioritarios para la intervención en materia de protección social, Madrid, Ministerio de Trabajo y Asuntos Sociales [rhttp:// www.seg-social.es/prdioo/groups/public/ documents/binario/097541.pdf〉].

COLECTIVO IOÉ (2001): Mujer, inmigración y trabajo, Madrid, Instituto de Migraciones y Servicios Sociales.

MARTÍN, M. J.; MORENO, G.; y FULLAONDO, A. (2012): Mujer inmigrante en la CAE, Bilbao, Ikuspegi-Observatorio Vasco de Inmigración.

MORENO, G.; y AIERDI, X. (coords.) (2011): Anuario de la Inmigración en el País Vasco 2010, IkuspegiObservatorio Vasco de Inmigración.

PARELLA, S. (2006): Las lógicas de la discriminación de las mujeres inmigrantes en el mercado de trabajo: mecanismos y repercusiones, Madrid, Puntos de Vista. 